\title{
Rivalry and Learning
}

\section{Among Clustered and Isolated Firms}

\author{
Cristina Boari Guido Fioretti Vincenza Odorici \\ University of Bologna \\ Department of Management
}

Contact Addresses:

cristina.boari@unibo.it, guido.fioretti@unibo.it, vincenza.odorici@unibo.it 


\section{INTRODUCTION}

Knowledge has become a crucial asset in modern production systems, and its creation has become a key process in order to sustain or increase competitiveness. The ensuing shift toward a knowledge-based economy has amplified research interests in geographical clustering of firms, for geographical proximity is supposed to ease inter-organizational learning.

Indeed, there is substantial empirical evidence claiming that firms located in geographical clusters are more likely to learn and innovate than isolated firms (Audretsch and Feldman, 1996; Baptista and Swann, 1998; Baptista, 2000; Wennberg and Lindqvist 2008). However, this renewed attention to the subject of geographical proximity highlights how far we are from having a clear understanding of its influence on interactive learning and innovation (Boschma, 2005; Torre and Gilly, 2000). In general, geographical proximity per se is not considered a sufficient condition for learning to take place (Boschma, 2005: 62), though it is clearly able to strengthen other factors that facilitate learning processes (Boschma, 2005; Boari et al., 2004; Breschi and Lissoni, 2005; Greeve, 2005). Many scholars starting from different perspectives converge to agree that all concurring factors should be related to one another in order to construct a theory of clustering processes where learning has a key role (Torre and Rallet, 2005; Knoben and Oerlemans, 2006; Malmberg and Maskell, 2002: 429).

This paper aims to make a contribution by investigating the relationships between geographical proximity and rivalry with respect to interactive learning and knowledge creation. This is quite unusual in the literature, for most theoretical developments and empirical tests have focused on inter-firm cooperation, whereas far less attention has been paid to the interplay of geographical proximity, rivalry and learning processes. 
This orientation is quite surprising, for rivalry is at the very heart of the concept of geographical cluster as a spatially concentrated group of firms that operate in the same industry. Indeed, claims that "knowledge in clusters is created through increased competition and intensified rivalry" (Malmberg and Power, 2005: 412) are widely shared.

In our contribution, we wish to explore the relationships between rivalry and geographical proximity at the very level of contacts between individual firms. In particular, we wish to highlight the influence of geographical proximity on rival identification, on the comparison of their knowledge, and on the consequent elaboration of a strategy.

In order to reproduce the interactions between firms, we made use of an agent-based model $(\mathrm{ABM})$ where the strategic choices of rival firms are derived from general assumptions on competitive behavior and learning processes. Aim of the model is to investigate the coevolution of firms' knowledge, strategies and performances.

The rest of this article is structured as follows. The second section provides the theoretical and conceptual framework of our work. The third section explains the elements of the model. The fourth section illustrates the experiments and their results. The fifth section concludes.

\section{THEORETICAL FRAMEWORK}

According to Baum and Sorenson (2003) the last few years have witnessed a rapid rise in interest in the topics of place and space in the social sciences. Economists, sociologists and strategy scholars have become particularly interested in studying the implications of the spatial distribution of firms for economic growth as well as its consequences on knowledge production and diffusion. In general, their assumption is that a critical mass of co-localized firms can promote knowledge production and circulation (Cowan, Jonard and Ozman, 2004). 
In particular, economic geographers have pointed out a need to understand the relationship between geographic proximity and the processes of localized learning and innovation, a relationship that has been overseen in the economic conceptualization of knowledge as an externality that spreads pervasively within a spatially bounded area (Giuliani, 2007) and can be easily reproduced (Cowan, Jonard and Ozman, 2004). A reconsideration of the nature of knowledge and of the problems connected to its reproduction and diffusion has increased the concern about other non-spatial dimensions of proximity relevant in promoting knowledge production and circulation (Boschma, 2005; Breschi and Lissoni, 2005; Knoben and Oelemans, 2006; Greeve, 2005). While geographic proximity is the least ambiguous concept involved (Knoben and Oerlemans, 2006), its explanatory power has been reduced by the possibility that organizational and relational proximities surrogate its effects (Gallaud and Torre, 2005; Torre and Rallet, 2005) shows. These different dimensions of proximity should be better specified and related to one another (Boschma, 2005: 62; Greeve, 2005).

Contrary to economics, the strategic perspective has rarely considered geographical proximity per se as a factor enabling learning processes. Rather, it has considered geographical proximity as a dimension promoting other mechanisms, such as cooperation and rivalry, that may facilitate learning processes. These mechanisms are at the very heart of the concept of a geographical cluster as a spatially concentrated group of firms that compete in the same or related industries and are connected through a set of vertical and horizontal relationships (Porter, 1990; 1998).

Although this general framework addresses both cooperation and competition, researchers mainly focused their attention on inter-firm cooperation induced by geographical proximity (see Knoben and Oerlemans, 2006 for an extensive review) and its consequences on learning processes (Dyer and Nobeka, 2000; Doz, 1996; Inkpen, 1998; Inkpen and Crossan, 1995; Kale, Singh and Perlmutter, 2000; Khanna, Gulati and Nohoria, 1998; Kogut, 1998; Powell, 
1998; Simonin, 1999). Far less attention has been paid to the impact of geographical proximity on rivalry and competition, as well as on their combined consequences on organizational learning and innovation. The only exceptions - which do not address the issue of geographical proximity, anyway - are the studies on inter-organizational collaborations among rivals and learning processes (Dussauge, Garrette and Mitchell, 2000).

These considerations suggested us to focus on rivalry. More specifically, the ensuing subsections deal first with the relationship between geographical proximity and rivalry and, subsequently, with the relationship between rivalry and learning.

\section{Geographical proximity and the identification of rivals}

On the relationship between geographical proximity and rivalry, scholars have expressed two opposite views. On the one hand, long-term observers of industrial clusters have noted that clustered firms exhibit more competition than non-clustered firms (Becattini, 1990; Dei Ottati, 1994; Enright, 1991). In fact, according to the theory of industrial organization rivalry involves a large number of local firms committed to a fight of all against all (Piore and Sabel, 1984). Allegedly, this contributes to the competitive advantage of a geographical area and of the firms clustered on it (Porter, 1990; Porter, 1998; Porter, Sakakibara and Takeuchi, 2000). On the other hand, researchers from the resource-based view claimed that geographical proximity allows an extreme division of labor within the cluster, and consequently, firms specialization. Thus, this reasoning suggests that rivalry is limited to a few competitors (Lazerson and Lorenzoni, 1999). Unfortunately, both interpretations lack any empirical verification.

A further source of confusion is the fact that too many researchers on geographical clusters have taken rivalry and competition as synonyms. In reality, since the early days of economic thinking the term competition has been used to identify firms that depend on the same 
resources (Baum and Korn, 1996: 225). On the contrary, rivalry has been interpreted as a conscious struggle by each individual firm to establish its own supremacy in a specific market (Scherer and Ross, 1990). Thus, rivalry and competition do not necessarily coincide.

Competition has been neglected because it is an "under-socialized" phenomenon occurring among actors that are anonymous to each other (Lomi and Larsen, 1996: 1293). Competition would be determined by market forces not subject to the conscious control of individual firms (Baum and Korn, 1996: 225). Consequently, it would not be influenced by geographical proximity (Torre and Gilly, 2000).

However, rivalry does not deserve the same treatment. Albeit of the same relational nature (Baum and Korn, 1999; Korn and Baum, 1999) as market interactions between dyads of firms (Chen and McMillan, 1992; Chen, 1996: 100), rivalry depends on firm-specific competitive conditions (Baum and Korn, 1996).

Among the two separate approaches to the study of rivalry, the rational-economic and the cognitive managerial (Baldwin and Bengtsson, 2004; Chen, 1996; Miller and Chen, 1996; Farjoun and Lai, 1997), it is the last one which contributed to the exploration of the role of geographical proximity as an explicit and implicit criterion to "market construction". According to Porac and Rosa (1996: 372), "Defining rivals is not so much a matter of overt behavior as it is one of managerial attention and discrimination", and also, "Rivalry occurs when one firm orients toward another and considers the actions and characteristics of the other in business decisions, with the goal of achieving a commercial advantage over the other" (Porac et al., 1995). Consequently, rivalry implies mutual recognition and only occurs between paired organizations that are each identifiable by the other one (Lomi and Larsen, 1996: 1293). 
In rivalry, but not in competition, cognitive processes matter. Whilst competitors may be regarded as a nebulous collective actor, rivals must be identified and comparisons with each of them must be made.

Cognitive processes make rivalry a localized phenomenon. In fact, several authors (Baum and Haveman, 1997; Baum and Mezias, 1992; Gripsrud and Gronhaug, 1985; Lant and Baum, 1995; Porac et al., 1995) claim that firms are most likely to identify neighboring competitors as rivals. A quite common explanation is the observability argument (Cyert and March, 1963), claiming that geographically proximate firms are most likely to be noticed and observed because proximity increases the availability of information and provides an incentive to attend to it (Porac at al., 1995).

However, Boari, Odorici and Zamarian (2003) did not find such a simple relation between rivalry and geographical proximity. These authors showed that, in an Italian cluster of producers of packaging machines, rivals were not necessarily selected among the competitors within the cluster. On the contrary, most rivals were identified among firms located outside the cluster. However, they also found that whenever firms did not cite any local rival, the total number of rivals they gave was consistently smaller. Thus, their research suggested a more complex relationship between geographical proximity and rivals identification.

Boari et al. (2004) advanced the idea that sharing geographical space with rivals may help to extend managerial representations, spreading entrepreneurs' monitoring attention over a larger number of rivals. This can be readily explained if one accepts that geographical proximity eases the consideration of rivals, and that entrepreneurs are boundedly rational decision-makers. Then, their fixed amount of cognitive resources can be either employed to attend a large number of geographically proximate rivals, or a small number of geographically distant rivals, or any combination of both. 


\section{Geographical proximity and learning processes}

The relationship between rivalry and learning has been neglected by the majority of the literature on inter-organizational learning (Ingram, 2002; Kraatz, 2003; Kim and Miner, 2007). In fact, in the few studies on the impact of rivalry on learning, rivals have been aggregated (Ingram and Baum, 1997; Aharonson, Baum and Feldman, 2004). On the contrary, dyadic relationships should be considered (Darr and Kurzburg, 2000).

However, the studies on inter-organizational learning and, before them, those on vicarious learning (Davies and Luthans, 1980; Manz and Sims, 1981; Gioia and Manz, 1986; Bandura, 1977) are indirect references to rivalry. A notable finding of these studies is that when learning is stimulated by the experiences of others, similarity is an orienting principle to choose from whom to learn (Darr and Kurtzberg, 2000). In fact, similarity reduces information uncertainty (Farjoun and Lai, 1997) creating a context of understanding. Since rivals are similar, their experiences are naturally salient (Ingram, 2002).

In particular, strategic similarities such as market overlap and product commonality are useful to identify the competitive arena and to influence information flows and learning processes (Porac, Thomas and Baden-Fuller, 1989). Similarity in strategy is expected to have its greatest impact on knowledge transfer (Darr and Kurtzburg 2000), at least because it is the main criterion to identify a set of comparable firms that offer experiences useful to define one's own behavior and role (White, 1981; White and Eccles, 1987).

Cognitive distance is still another type of similarity, which is crucial to identify the rivals to imitate. Cognitive distance measures the different way to perceive, interpret and evaluate the world by two actors (Nooteboom, 2004; Boschma, 2005). The notable feature of cognitive distance is that it neither be to high nor to low for learning to take place. In fact, too high a cognitive distance means that the two actors have so different mental categories that each of them is unable to understand what the other is doing. At the other extreme, too low cognitive 
distance means that the two actors are so similar, that they have nothing to learn from one another.

The attention payed by many scholars to the concept of similarity implicitly concedes that, through monitoring and comparison, rivalry influences the learning processes (Malmberg and Maskell, 2006). However, some scholars have expressed doubts about the quality of what can be learned from rivals. First of all, rivalry discounts the idea that learning from the experience of others may be less important than learning by direct search and experimentation. Moreover, learning by monitoring and comparing (as in rivalry) is considered to contribute less valuable knowledge with respect to learning by interacting (as in collaboration) (Lane and Lubatkin, 1998). In fact. establishing comparability through sharing of strategic and cognitive repertoires is supposed to give access only to codified knowledge, whereas interacting with the other organizations may allow to understand the more tacit components of knowledge.

Geographical proximity is supposed to ease learning. Boari, Odorici and Zamarian (2003) suggest that the depth of the comparison with rivals increases with the geographical proximity of rivals. Geographical proximity could increase the variety that firms perceive in the environment (Nooteboom, 2004) and enlarge the number of strategic aspects that firms takes in consideration (Bogner and Thomas, 1993). In fact, when firms observe distant rivals the complexity of their cognitive representations gets lost (Morgan, 2004), both because distance weakens the collection of information and their interpretation (Ghoshal and Kim, 1986) and because it decreases the speed of any response (Yu and Cannella, 2007).

However, some authors suggest that geographical proximity may have a negative side effect. In fact, if learning is limited to proximate rivals, myopia is likely to ensue (Levitt and March, 1988; Levinthal and March, 1993). 


\section{THE MODEL}

We constructed a model of competitive interactions between clustered firms that enlarge or shrink their knowledge while undertaking strategic actions with respect to their rivals. This section illustrates the building blocks of our model and, in its final part, how they are connected to one another.

\section{The knowledge of firms}

We assumed that knowledge articulates into knowledge fields. Each knowledge field is a combination of a product and a market. For instance, if a firm produces one product for two markets, this knowledge is expressed by two knowledge fields: one for the product and market 1 , the other of the product and market 2 .

Figure (1) illustrates knowledge fields as parallelepipeds composed by a product and a market. The number of knowledge fields owned by a firm is not constant with time. In fact, firms can start to operate in a new field, or they can leave a field if their managers deem that it is no longer worth pursuing.

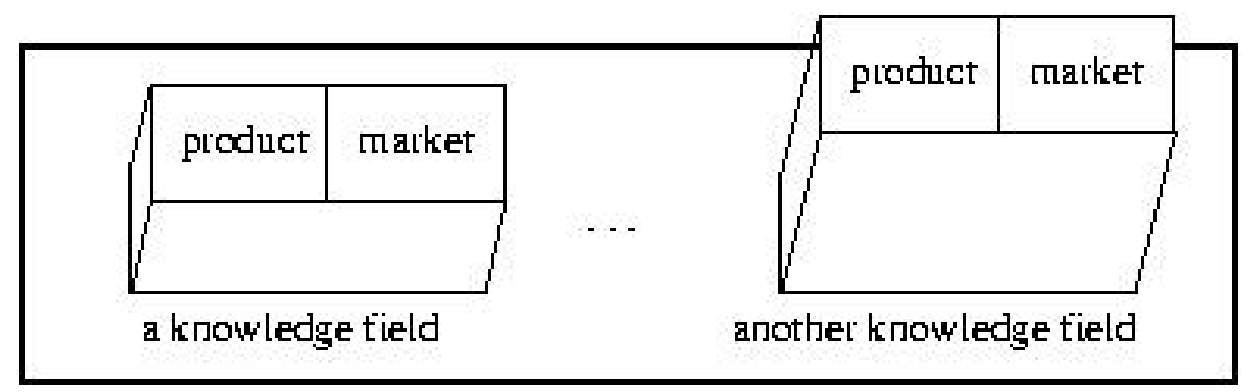

Figure 1. A firm's knowledge is entailed in knowledge fields, represented by parallelepipeds. Each knowledge field spans a product and a market. The height of a parallelepiped represents the depth of knowledge in a specific field. 
Knowledge fields are characterized by a depth $d \in[0,1]$. The depth of a knowledge field owned by a firm represents how good a firm is in that field. In figure (1), depth is represented by the heights of parallelepipeds.

The depth of knowledge decays with time or, conversely, is increased by efforts to develop in-house knowledge or by the imitation of rivals. By assuming that depth is limited in the $[0,1]$ interval we implied that, for any combination of a product and a market, knowledge can only increase up to a maximum in any given field.

Since we are modeling small firms with a limited managerial attention implied by human bounded rationality (Simon 1947), we also assumed that the sum of all depths of all knowledge fields cannot be greater than one. So if a firm has $N$ knowledge fields $\mathrm{A}_{1}, \mathrm{~A}_{2}, \mathrm{~K} \mathrm{~A}_{N}$, each characterized by a depth $d_{i} \in[0,1]$, it is also $\sum_{i}^{N} d_{i} \leq 1$.

If the depths of knowledge fields $\mathrm{A}_{1}, \mathrm{~A}_{2}, \mathrm{~K} \mathrm{~A}_{N}$ do not sum up to unity, a depth $d_{N+1}$ is added such that $\sum_{i=1}^{N+1} d_{i}=1$. The amount $d_{N+1}$ measures the extent to which the cognitive capabilities of the decision-makers in the firm are not employed in any field, making cognitive resources available for deepening the existing knowledge or considering novel knowledge fields. Henceforth, this depth will be referred to a virtual knowledge field $\mathrm{A}_{N+1}$.

The existence of a particular knowledge field, as well as its similarity to other knowledge fields, is common knowledge (Malmberg and Maskell, 2002: 439). This means that all firms know that certain products exist and that they are sold in certain markets.

However, only the firm that owns a particular knowledge field knows its depth exactly. The other firms know only a fraction of this depth, depending on their geographical proximity. The further they are, the less they know how a certain product is actually made and sold in a 
certain market. We assume that depth decreases linearly from its original value, attained at maximum geographical proximity, down to zero for two firms that are as far as possible from one another as it is allowed by the model.

\section{Rivals identification and geographical proximity}

Rival firms are selected among those firms whose knowledge is sufficiently similar. Similarity is measured on pairwise comparison of one's knowledge fields with those of a potential rival.

For each pair of knowledge fields it is observed whether they concern the same product ( $\operatorname{similarity} 1 / 2$ ), or they deal with the same market (similarity $1 / 2$ ), or both (similarity 1 ). The sum of these numbers is normalized to the $[0,1]$ interval to yield an index of the similarity of the knowledge of the two firms.

Our model rests on the assumption that considering a rival requires some cognitive effort by the main manager of a small firm, whose maximum cognitive effort is limited by her bounded rationality (Simon 1947). In accordance with empirical findings by Boari, Odorici and Zamarian (2003), the cognitive effort for entertaining a rival can be assumed to decrease with physical proximity.

We shall assume that each firm entertains a list of rivals such that the sum of the cognitive efforts to entertain them is lower than an amount specified by an exogenous parameter. By this assumption, since cognitive effort decreases with physical proximity, firms who focus on geographically close rivals may typically consider a large number of rivals. This result is in accordance with our preliminary empirical findings (Boari, Odorici and Zamarian, 2003).

\section{Cognitive distance from rivals}


At each simulation step, a firm picks up a rival at random from its list of current rivals. For each of its knowledge fields it scans the rival's knowledge fields and it evaluates the cognitive distance between each pair of knowledge fields.

The cognitive distance between two knowledge fields is measured by the extent to which knowledge fields do not overlap: Identical knowledge fields have cognitive distance 0 , knowledge fields with identical products (markets) but different markets (products) have cognitive distance $1 / 2$, knowledge fields with different markets and different products have cognitive distance 1 .

Note that the fewer the rivals, the less likely that the evaluation of cognitive distance is different at each step. Conversely, firms with many rivals are more likely to measure diverse values of cognitive distance, depending on which rival they are picking up.

\section{Evaluation of performance}

Past performances are considered a major explanatory variable of organizational learning (Cyert and March, 1963; Lenvinthal and March, 1981). However, measuring performances of changing knowledge is not a trivial task. In fact, since the outcomes of innovative activities cannot be foreseen, ex-ante evaluation by means of utility functions makes little sense.

An alternative route is to conceive the usefulness of a piece of knowledge as deriving from its connections to other pieces of knowledge (Villani et al., 2007). For instance, a possible explanation of the success of innovations is their ability to connect with other products creating new markets (see Actor Network Theory in the box). Following this interpretation, we are led to ascribe the performance of knowledge to its ability to bridge structural holes (Burt, 1992). 
Let us interpret common knowledge as a directed weighted graph, where nodes are knowledge fields and edges are common instances of business elements. Thus, the ability to bridge structural holes is measured by betweeness centrality:

$$
g_{i}=\frac{1}{(n-1)(n-2)} \sum_{s \neq i \neq t} \frac{\sigma_{s i t}}{\sigma_{s t}}
$$

where $\sigma_{s t}$ is the number of minimum paths between node s and node t, $\sigma_{s i t}$ is the number of minimum paths between node $s$ and node $t$ passing through node $i$ and $n$ is the number of nodes. The normalization factor ensures that $g_{i} \in[0,1], \forall i$.

Figure (2) illustrates a network of knowledge fields, each composed by a product and a market. Knowledge fields are inscribed in dashed circles, which represent the firms that own them. A link is there whenever two knowledge fields concern the same product, or the same market. In general, the knowledge of a firm may span several fields. Occasionally, different firms may have the same knowledge field.

In figure (2), firm $\varepsilon$ owns knowledge fields that constitute the only bridge between the knowledge fields of firms $\alpha, \beta$ on the one side, and $\gamma, \delta$ on the other side. Thus, these knowledge fields are essential for the knowledge in the economy to be connected. It is knowledge fields of this kind that, according to eq.(1), have a high betweeness centrality and therefore a high performance. On the contrary, the only knowledge field of firm $\gamma$ has a low betweeness centrality. 


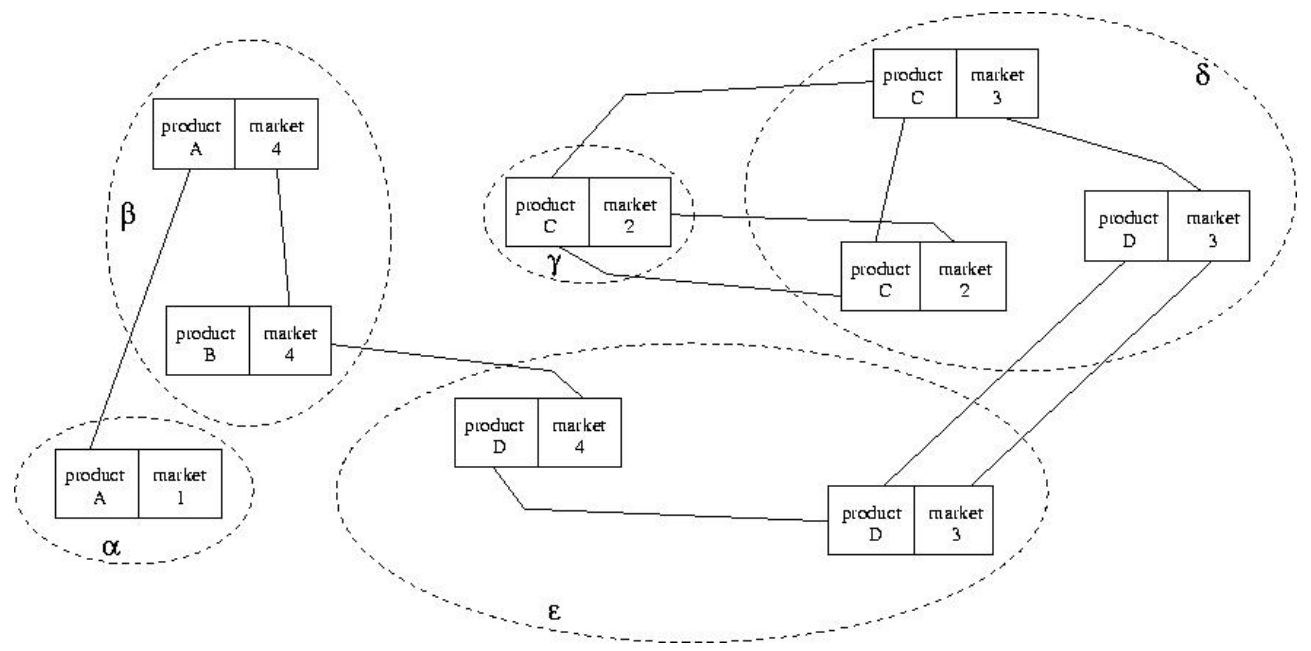

Figure 2. A network of knowledge fields (solid squares) owned by firms (dashed circles). Products are labeled by letters A, B, C, D. Markets are labeled by numbers 1, 2, 3, 4. Firms are labeled by Greek letters $\alpha, \beta, \gamma, \delta, \varepsilon$.

However, by measuring performance by means of betweeness centrality we never assign a high performance to novel knowledge. In fact, if a firm with entrepreneurial spirit creates an entirely novel field, this is by definition different from previous knowledge fields and, in general, connects none.

In the network of knowledge fields, an innovative knowledge field is an isolated node or a node with one single link to the other nodes, bridging none. In figure (2), the knowledge field owned by firm $\alpha$ is one such case. Henceforth, the performance of an innovative knowledge field will be drawn randomly from the $[0,1]$ interval. 


\section{ACTOR NETWORK THEORY}

Actor network theory (ANT) is a sociological theory where the development and acceptance of artifacts and technologies is understood in terms of the interests of various social actors. ANT stresses that different actors may have a different understanding of the properties and potentialities of novel artifacts and technologies; nonetheless, their interests may align to support a particular innovation. In their turn, artifacts and technologies change the balance of powers and the network of relationships between social actors. Equipped with this view, scholars working with ANT have provided historical reconstructions where the development of particular artifacts and technologies is described as the - sometimes unintended - consequence of the work of a large number of actors rather than the visionary plan of an isolated genius (Hughes, 1986).

In order to understand how ANT relates to our measure of performance, let us consider the following empirical investigations of successful innovations:

- Law (1986) explained the rise of Portuguese ability to exert long-distance control in the XV century through certain simplifications of medieval astronomy that made it available to navigators, a new design of vessels that enabled them both to carry large freights and to resist armed attacks, and increased reliability of mariners through extensive drill. The Portuguese ability to exert control as distant as India would derive from the ability of a small committee set out by King John "The Navigator" to embed the results of medieval astronomy in a few simple tools that could be operated without prior knowledge of astronomy.

- Latour (1988) described the rise of Louis Pasteur and the diffusion of vaccination as a collective outcome of several forces, of which the most important ones were the hygienist movement, that was seeking scientific support for its urban planning prescriptions, the surgeons, who could improve the effectiveness of their art by means of local disinfection, and the military, which did not want its soldiers to be decimated by tropical diseases. On the contrary, physicians opposed vaccination for several decades, until Pasteur proposed post-infection treatments and, most importantly, the State provided a role to physicians in the compulsory vaccination of the French population.

In both cases, we see one or a few actors - Louis Pasteur, King John and his astronomers - who were able to place themselves in a position from which they could exert a great influence because powerful allies are there to wait for their innovations the hygienists in the case of Pasteur, the merchants with their improved vessels in the case of King John.

A consequence that we may drawn is that successful innovations are those that are able to bridge between existing bodies of knowledge. From this insight our choice follows, to measure the performance of a knowledge field by means of its betweeness centrality in a graph where nodes are knowledge fields, connected by edges if they have a product or a market in common - see e.g. figure (2). 


\section{Inter-organizational learning}

Each firm scans its own knowledge fields and the knowledge fields of the selected rival. For each pair knowledge fields, a firm must choose one among the following courses of action (Bandura, 1977; Davies and Luthans, 1980; Manz and Sims, 1981; Gioia and Manz, 1986):

1. It may develop its own knowledge, which we call experimental learning;

2. It may learn through imitation of what others learned, which we call vicarious learning;

3. It may do nothing, which we call inaction;

4. It may decide to abandon its own knowledge field, which we call exit.

According to previous studies, the two factors that determine the choice made by a firm are past performance and cognitive distance from rivals. Their findings may be summarized as follows.

Poor past performances and rivals pressure give firms the impetus to undertake experimental learning (Tushman and Romanelli, 1985; Swaminathan and Delacroix, 1991). Likewise, good past performances may also foster experimental learning, simply because large amounts of resources are available (Cyert and March, 1963). On the contrary, intermediate past performances are mostly responsible for inertial behavior, because: 1) they induce managers to believe they have gotten it right, 2) they induce managers to interpret past performances as a sign that less vigilance and less environmental scanning or search are required, 3) they assure leaders the status and resources to perpetuate their power, 4) they induce managers to attribute success to their own actions (Miller and Chen, 1994; Lant, Milliken and Batra, 1992).

So far it concerns cognitive distance, it favors transfers of knowledge when it takes intermediate levels (Nooteboom, Van Haverbeke, Duysters, Gilsing and van den Oord, 2007). In fact, knowledge at a too low cognitive distance might be too similar to be 
interesting, whereas knowledge at a too high cognitive distance is likely not to be understood. Thus, vicarious learning is expected to occur at intermediate levels of cognitive distance. Inaction is the default option when the levels of performance and cognitive distance do not allow any action. The depth of knowledge fields decays with time, so if learning does not intervene to restore depth, it may shrink to zero. In this case a knowledge field is abandoned, and this is exit.

The above considerations suggest that behavior depends on whether performance and cognitive distance are low, intermediate, or high. In order to distinguish three intervals, we must provide the model with two exogenous thresholds.

Cognitive distance will be low if it is lower than a threshold $\mathrm{S}_{\mathrm{L}}$, it will be high if it is higher than a threshold $\mathrm{S}_{\mathrm{H}}$ and it will be intermediate if it lies between $\mathrm{S}_{\mathrm{L}}$ and $\mathrm{S}_{\mathrm{H}}$. Likewise, performance will be low if it is lower than a threshold $\mathrm{T}_{\mathrm{L}}$, it will be high if it is higher than a threshold $\mathrm{T}_{\mathrm{H}}$ and it will be intermediate if it lies between $\mathrm{T}_{\mathrm{L}}$ and $\mathrm{T}_{\mathrm{H}}$. All thresholds take values in the $[0,1]$ interval.

Figure (3) illustrates the dependence of behavior from performance and cognitive distance as characterized above. Exit is not illustrated because it does not occur instantaneously if performance and cognitive distance take certain values, but only once depth has shrunk to zero. 


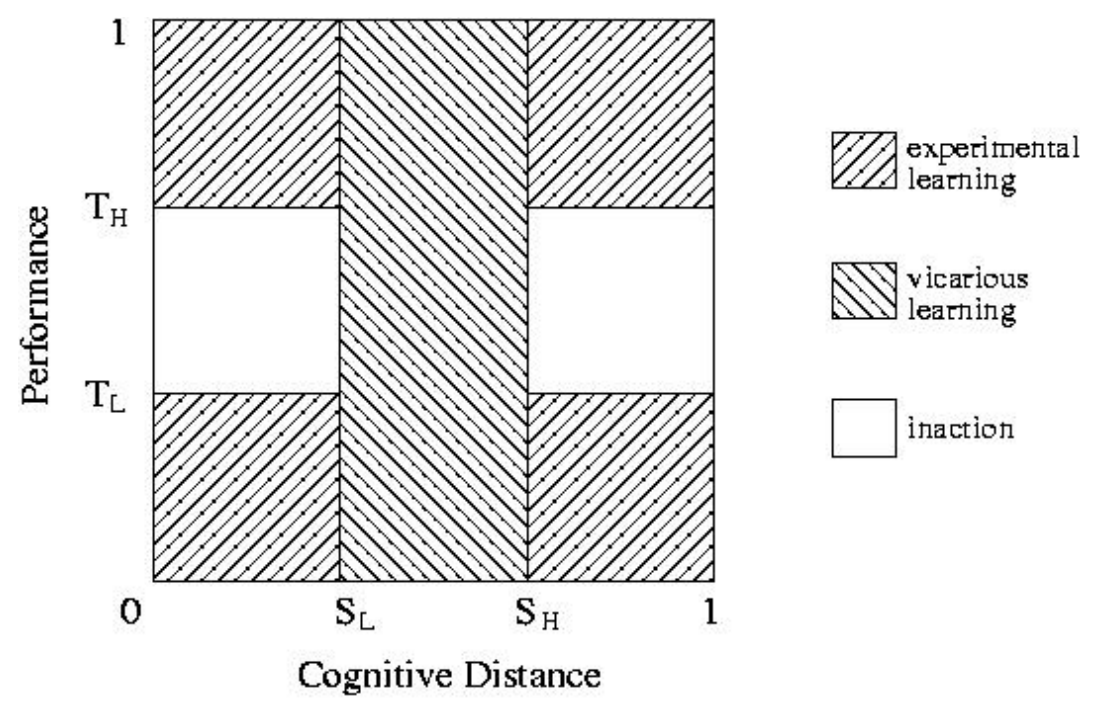

Figure 3. Experimental learning, vicarious learning and inaction depending on cognitive distance and performance.

\section{The flow chart}

The previous building blocks are arranged together in a sequence of operations illustrated in figure (4). For simplicity, only two firms have been considered. 


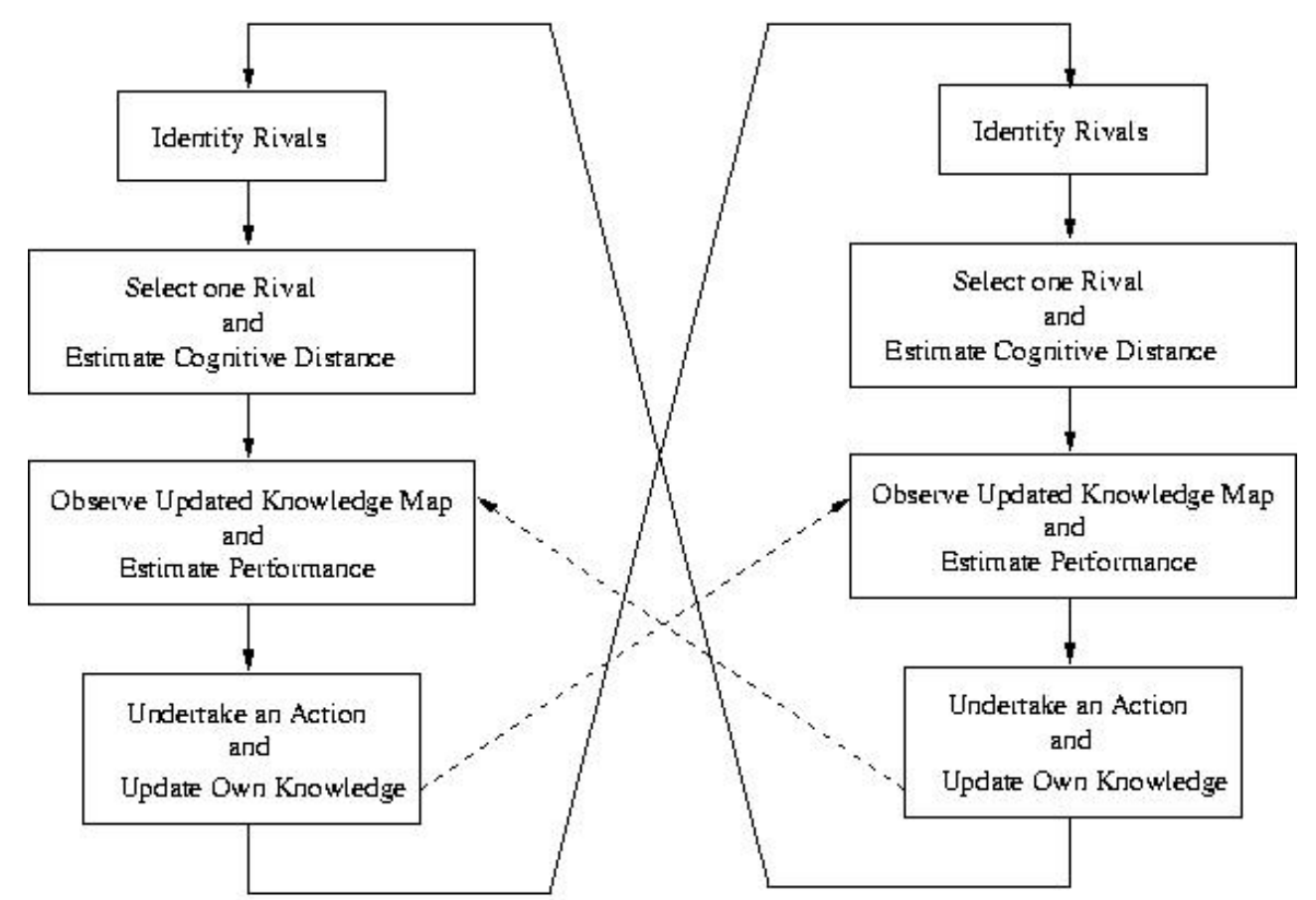

Firm A

Firm B

Figure 4. The sequence of operations carried out by a firm A and their relationships with the analogous sequence carried out by another firm B.

Consider firm A in figure (4). Top to bottom, the squares describe the sequence of operations that it carries out. First, it identifies its rivals. Subsequently, it randomly selects one of them and estimates its cognitive distance. Then it observes the graph of all knowledge present in the economy and calculates the performance of its own knowledge. Finally, it undertakes an action and, consequently, its own knowledge changes. Before repeating this sequence, firm A has to wait that firm B undergoes a similar sequence.

Note that the evaluation of performance depends on the actions that were undertaken by all other firms in the previous steps. This is the meaning of the dotted arrows in figure (4).

\section{Initialization}

Firms are placed on a torus obtained from a square of $100 \times 100$ pixels. Firms do not move on this space. 
In order to evaluate the effects of clustering, both clustered and isolated firms are considered at the same time, and the number of isolated firms is set equal to the number of clustered firms. Isolated firms are distributed uniformly in space.

Our model allows to choose the number of clusters, the number of firms in each cluster, and the geographical proximity of clusters. The number of clustered firms is obtained by the product of the number of firms in a cluster by the number of clusters. The geographical proximity of clusters depends on the variance of a normal distribution of the position of clusters.

Firms are created with an initial wealth. Following the empirical evidence on the distribution of (however measured) size of firms, wealth is initially distributed according to a Zipf law (Axtell, 2001; Gaffeo, Gallegati and Palestrini, 2003). The values obtained by the Zipf distribution have been scaled by the length of the square from which the torus is derived, where firms are placed (see above). In fact, the absolute size of firms depends on the size of their market, and the size of the world where firms operate is a proxy for market size.

Performance adds to the wealth of firms, but both experimental and vicarious learning require expenditures. If the wealth of a firm decreases down to the point where no learning is possible, then the firm dies. A dead firm is immediately replaced by a new one that occupies the same geographical position. Its initial wealth is drawn from the same power law as above. Firms are initialized with a random number of knowledge fields drawn from a uniform distribution. The maximum number of knowledge fields per firm is a parameter of the model. The number of different products and the number of different markets by which these initial knowledge fields are composed is also drawn from a uniform distribution. The maximum number of initial products and markets is obtained multiplying the number of knowledge fields per firm by the number of firms. 


\section{THE EXPERIMENTS}

We carried out simulations in order to compare the actions undertaken, results obtained and knowledge learned by clustered firms with respect to isolated firms. Since we were interested in long-term regularities, for any chosen parameters combination we let the model run with different seeds for 1,000 steps and observed its behavior at simulation end.

\section{The choice of parameters}

Our simulations highlighted that clusters of firms are efficient only if they reach a critical mass in terms of the number of firms that they entail. According to our model, only if a cluster entails at least 40-50 firms do these firms obtain substantial advantages with respect to isolated firms.

Our model is a simplification of reality so the above value should not be understood as the minimal size a cluster should have in the real world. However, it implies that in the real world a threshold exists, above which a cluster is viable. On the contrary, too small clusters offer no advantage to their members.

Some experimentation with the parameters that regulate the number, size and geographical proximity of clusters highlighted that small but geographically proximate clusters offer the same advantages to their members as one large cluster (e.g., 5 clusters of 10 firms each, at a distance of less than 10 pixel from one another, are equivalent to one single cluster of 50 firms). On the contrary, small clusters far from one another offer no advantage with respect to isolated firms. 
We focused our simulations on the comparison between one single cluster of 50 firms and other 50 firms scattered around. The number 50 was chosen because it is roughly the minimum cluster size where the advantages of clustering become evident.

The following parameters have proven not to have a strong influence on the outcomes of our simulations: the costs of experimental learning and vicarious learning, the thresholds for performance and cognitive distance, the coefficient for the natural decay of wealth and depth of knowledge with time, and the maximum number of knowledge fields that can be managed by one firm. Although these parameters do have an influence on the numerical values produced by the model, they do not produce any qualitative change of the implications of the model.

Given that performance - as it is computed by betweeness centrality - ranges in the $[0,1]$ interval, the costs of imitation (vicarious learning) and experimentation (experimental learning) have been set at 0.01 whenever one such action would be undertaken by a firm. The thresholds of performance and cognitive distance have been set at 0.4 for the lower thresholds and 0.6 for the upper thresholds, respectively. In this way, the unit interval is quite equally spaced. The rate of decay has been set at 0.01 in order to keep firm deaths at a minimum. Finally, the maximum number of knowledge fields has been set at 5 in accordance with psychological experiments pointing to some point between 4 and 7 as the maximum number of items that can be managed by a human mind (Miller, 1956; Cowan, 2000).

The cognitive parameters governing the number of rivals, i.e. the maximum cognitive effort and the similarity threshold above which a firm can be considered a rival, have a strong impact on the model and are able to change its qualitative conclusions. This happens because the number of rivals impacts on the knowledge with which a firm compares its own knowledge, and this comparison is the main determinant of its actions. 
The available empirical evidence suggests that the average number of rivals may be in the order of 2, 3, 4 or 5; only exceptionally a firm may mention something like 8-10 rivals, or no rival at all (Boari, Odorici and Zamarian, 2003; Russo and Pirani, 2001). We found that by setting the maximum cognitive effort at 0.3 (within the $[0,1]$ interval) and the similarity threshold at 0.1 (within the [0,1] interval) the simulations are in good accord with the empirical evidence.

\section{The results}

We expound the results of our model following the same sequence illustrated in figure (4). Identification of rivals

Clustered firms have, on average, many more rivals than isolated firms (5.7 vs. 1.8 rivals). Moreover, the one clustered firm that has more rivals than any other clustered firm, has many more rivals than the one isolated firm that has more rivals than any other isolated firm (11 vs. 5 rivals).

Clustered firms find most of their rivals inside their own cluster (on average, 4.9 rivals inside their own cluster and 0.8 rivals outside it).

\section{Cognitive Distance}

Clustered firms are at a higher cognitive distance from their rivals than isolated firms are from their rivals. In other words, clustered firms watch rivals whose knowledge is more different from their own knowledge, than isolated firms do.

\section{Performance}

Our simulations confirm all empirical evidence claiming that clustered firms have an advantage over isolated firms. In particular, we find out that clustered firms have a higher performance than isolated firms. Consequently, in our model isolated firms die (and are replaced) much more often than clustered firms. 


\section{Vicarious Learning and Experimental Learning}

According to our simulations, vicarious learning occurs much more often than experimental learning, both for clustered and isolated firms. This is quite surprising, given the importance attached to innovation by all economic theorizing.

However, our model does not deny that experimental learning is conceptually more important than vicarious learning. It simply suggests that, given the alleged conditions for experimental learning and vicarious learning, the latter is likely to occur more often than the first one.

\section{Knowledge Development}

We introduced two indicators of the development of firm knowledge. The first indicator is the number of knowledge fields managed by a firm. The second indicator is the depth of these knowledge fields. On both indicators, clustered firms perform better than isolated firms. Clustered firms have on average more knowledge fields than isolated firms, and their knowledge on these fields is deeper than the knowledge of isolated firms.

\section{CONCLUSIONS}

This study addressed the link between geographical proximity and rivalry as a cognitive and social dimension of competition. In particular, we investigated the relationship between geographical proximity and rivalry with respect to their impact on the development of knowledge by both agglomerated and isolated firms.

As we mentioned before, the relationship between geographical proximity and rivalry has been considered a crucial issue in the explanation of the competitive advantage of the geographical clusters and of clustered firms. In particular, geographical proximity is supposed to foster innovation and diffuse best practices through rivalry. However this is presumption rather than 
the result of empirical investigations. In our model we take this presumption together with the thesis of those scholars that, adopting a cognitive approach to the study of rivalry, considered geographical proximity as a powerful cognitive tool used to "construct" the market trough rivals" identification and comparison. In particular, in our model geographical proximity influences rivalry by reducing the cognitive effort necessary to entertain a rival and increasing the possibility to appreciate a rival's knowledge depth. Rivalry in this model assumes the character of a localized phenomenon, where nearest competitors may become rivals because geographical proximity increases information availability and provides an incentive to attend to it.

We believe this study can improve our understanding of the role played by geographical proximity in the cognitive representation of a market. In particular, according to our simulations geographical proximity allows to expand the borders of the constructed competitive environment by affecting the amplitude and the depth of the knowledge developed. Thus, geographically clustered firms have an advantage over isolated firms with respect to their ability to develop knowledge and adapting it to changing circumstances.

According to our simulations, clustered firms excel both in the number of knowledge fields and in their depth. This is interesting, because the extension and the depth of knowledge are often regarded as substitutes. Our model suggests it is possible for clustered firms to improve both. It is possible because clustered firms observe many more rivals than isolated firms, but most importantly because clustered firms have almost complete access to the depth of their rivals' knowledge, so imitation is quite easy.

Thus, the greater knowledge of clustered firms depends on another crucial outcome of our model, namely the prevalence of vicarious learning on experiential learning. Most of the time, learning does not occur through direct experience but rather trough the experiences of rivals, so having the possibility of drawing from others' experience makes for a crucial advantage.

Our simulations highlight that even in the knowledge economy, geographical clustering matters. It matters because geographical proximity helps establishing and maintaining social relations and, 
among them, rivalry relations. It is because of rivalry relations that knowledge is created, and it is through rivalry relations that knowledge is imitated. Our model, even in this basic version, reproduces these mechanisms. 


\section{REFERENCES}

Audretsch, D., Feldman, M. (1996) R\&D spillovers and the geography of innovation and production. American Economic Review, 86: 630-640.

Axtell, R.L. (2001) Zipf distribution of U.S. firm sizes. Science, 293: 1818-1820.

Baldwin, A. and Bengtsson, M. (2004) The emotional base of interaction among competitors - an evaluative dimension of cognition. Scandinavian Journal of Management, 20: 75-102.

Baptista, R. (2000) Do innovations diffuse faster within geographical clusters? International Journals of Industrial Organization, 18: 515-535.

Baptista, R. and Swann, P. (1998) Do firms in cluster innovate more? Research Policy, 27: 525-540.

Baum, J. and Haveman, H. (1997) Love thy neighbor? Differentiation and agglomeration in the Manhattan Hotel industry, 1898-1990. Administrative Science Quarterly, 42: 304-338.

Baum, J. and Mezias, S. (1992). Localized competition and organizational failure in the Manhattan hotel industry, 1898-1990. Administrative Science Quarterly, 37: 580-604.

Baum, J. and Korn, H. (1996) Competitive dynamics of interfirm rivalry. Academy of Management Journal, 39: 255-291.

Baum, J. and Korn, H. (1999) Dynamics of dyadic competitive interaction. Strategic Management Journal, 20: 251-278.

Becattini, G. (1990) The Marshallian industrial district as a socio-economic notion. In F. Pyke, G. Becattini and W. Sengenberger (Eds.), Industrial districts and inter-firm cooperation in Italy (pp. 37-51). Geneva: International Institute for Labour Studies.

Boari, C., Odorici, V. and Zamarian, M. (2003) Cluster and rivalry: does localization really matter? Scandinavian Journal of Management, 19: 467-489.

Boari, C., Espa, G., Odorici, V. and Zamarian, M. (2004) Space in cognition and cognition in space: rivalry within and outside an industrial cluster. Working paper presented at the XX Egos Colloquium.

Boggs, J. Rantisi, N. (2003) The relational turn in economic geography. Journal of Economic Geography, 3: 109-116.

Bogner, W. and Thomas, H. 1993. The role of competitive groups in strategy formulation: A dynamic integration of two competing models. Journal of Management Studies, 30: 51-67.

Boschma, R. (2005) Proximity and innovation: a critical assessment. Regional Studies, 39: 61-74.

Breschi S. and Lissoni F. (2005) Mobility of inventors and the geography of knowledge spillovers. New evidence on US data, Centro di Ricerca sui Processi di Innovazione e Internazionalizzazione, WP N. 184.

Burt, R. (1992). Structural holes: The social structure of competition. Cambridge, MA: Harvard University Press.

Chen, M. (1996). Competitor analysis and interfirm rivalry: Toward a theoretical integration. Academy of Management Review, 21: 100-134.

Chen, M. and MacMillan I. (1992). Nonresponse and delayed response to competitive moves: the roles of competitor dependence and action irreversibility. Academy of Management Journal, 35: 539-370.

Cowan N. (2000) The magical number 4 in short-term memory: a reconsideration of mental storage capacity. Behavioral and Brain Sciences, 24: 87-185.

Cowan R., Jonard N. and Ozman M. (2004) Knowledge dynamics in a network industry. Technological Forecasting and Social Change, 71: 469-484.

Cyert R. and March J. (1963) A behavioral theory of the firm. Prentice-Hall, Englewood Cliffs. 
Darr, E. and Kurtzberg, T. (2000) An investigation of partner similarity dimensions on knowledge transfer. Organizational behavior and human decision processes, 82: 28-44.

Dei Ottati, G. (1994). Cooperation and competition in the industrial district as an organization model. European Planning Studies, 2: 463-483.

Enright, M. J. (1991). Geographic concentration and industrial organization. Cambridge, MA: Harvard University.

Farjoun M. and Lai L. (1997) Similarity judgments in strategy formulation: role, process and implications. Strategic Management Journal, 18: 255-273.

Gaffeo E., Gallegati M. and Palestrini A. (2003) On the size distribution of firms: additional evidence from the G7 countries. Physica A, 324: 117-123.

Giuliani, E. (2007) The selective nature of knowledge networks in clusters: evidence from the wine industry. Journal of Economic Geography, 7: 139-168.

Greeve H. (2005) Interorganizational learning and heterogeneous social structure. Organization Studies, 26: 1025-1048.

Gripsrud, G. and Gronhaug, K. (1985) Structure and strategy in grocery retailing: A sociometric approach. The Journal of Industrial Economics, 32: 339-347.

Ingram P. (2002) Interorganizational learning, in Baum J. (ed.), The Blackwell Companion to Organizations. Oxford, Blackwell Publishers.

Knoben J. and Oerlemans L. (2006) Proximity and inter-organizational collaboration: A literature review. International Journal of Management Reviews, 8: 71-89.

Lant T., Milliken F. and Batra B. (1992) The role of managerial learning and interpretation in strategic persistence and reorientation: an empirical exploration. Strategic Management Journal, 13: 585-608.

Lant, T. and Baum, J. (1995). Cognitive sources of socially constructed competitive groups: Examples from the Manhattan hotel industry. In Scott, R. and Christensen, S. (eds.), The institutional construction of organizations (pp. 15-38). Thousand Oaks: Sage Publications.

Lazerson, M. and Lorenzoni, G. (1999). The firms that feed industrial districts: a return to the Italian source. Industrial and Corporate Change, 8: 235-266.

Levinthal D. and March J. (1993) The myopia of learning. Strategic Management Journal, 14: 92-112.

Lomi, A. and Larsen, E. (1996). Interacting locally and evolving globally: A computational approach to the dynamics of organizational population. Academy of Management Journal, 39: 1287-321.

Malmberg A. and Maskell P. (2002). The elusive concept of localization economies: toward a knowledge-based theory of spatial clustering. Environment and Planning A, 34: 429-449.

Malmberg A. and Maskell P. (2006) Localized learning revisited. Growth and Change, 37: 118.

Malmberg A. and Power D. (2005) (How) do (firms in) clusters create knowledge? Industry and innovation, 12: 409-431.

Miller, D. and Chen, M. (1994) Sources and consequences of competitive inertia: a study of the U.S. Airline Industry. Administrative Science Quarterly, 39: 1-30.

Miller, D. and Chen, M. (1996). The simplicity of competitive repertoires: An empirical analysis. Strategic Management Journal, 17: 419-439.

Miller, G.A. (1956) The magical number seven, plus or minus two: some limits on our capacity for processing information. The Psychological Review, 63: 81-97.

Morgan, K. (2004). The exaggerated death of geography: learning, proximity and territorial innovation systems. Journal of Economic Geography, 4: 3-21.

Nooteboom, B. (2006) Innovation, learning and cluster dynamics. in B. Asheim, P. Cooke and R. Martin (eds.), Clusters and regional development, London:Routledge (pp. 137-163). 
Nooteboom , W . Van Haverbeke , G . Duysters , V . Gilsing , A . van den Oord (2007) Optimal cognitive distance and absorptive capacity . Research Policy, 36:1016 - 1034.

Piore, M. and Sabel, C. (1984). The second industrial divide. New York: Basic Books.

Porac, J. and Rosa, J. A. (1996). Rivalry, industry models, and the cognitive embeddedness of the comparable firm. In P. Shrivastava, A. Huff and J. Dutton (eds.), Advances in Strategic Management (pp. 363-388). Greenwich, JAI Press.

Porac, Thomas and Baden-Fuller (1989) Competitive groups as cognitive communities: The case of Scottish knitwear manufacturers, Journal of Management Studies, 26: 397-416.

Porac, J., Thomas, H., Wilson, F., Paton, D. and Kanfer, A. (1995). Rivalry and the industry model of Scottish knitwear producers. Administrative Science Quarterly, 40: 203-227.

Porter, M. (1990). The competitive advantage of nations. New York: The Free Press.

Porter, M. (1998). Clusters and the new economics of competition, Harvard Business Review, 76: 77-90.

Porter, M., Sakakibara, M. and Takeuchi, H. (2000). Can Japan compete?. London, MacMillan.

Russo, M. and Pirani, E. (2001). Metalnet. Struttura e dinamica dei cambiamenti nelle relazioni tra le imprese metalmeccaniche in provincia di Modena. Primi risultati dell'indagine empirica. Università di Modena e Reggio Emilia.

Scherer, F. and Ross, D. (1990). Industrial market structure and economic performance. Boston, Houghton Mifflin.

Simon H.A. (1947) Administrative Behavior. London, MacMillan.

Swaminathan A. and Delacroix J. (1991) Differentiation within an organizational population: additional evidences from the wine industry. Academy of Management Journal, 34: 679692.

Torre A. and Gilly, J. (2000) On the analytical dimension of proximity dynamics. Regional Studies, 34: 169-180.

Torre A. and Rallet, A. (2005) Proximity and localization. Regional Studies, 39: 47-59.

Tushman M. and Romanelli E. (1985) Organizational evolution: A metamorphosis model of convergence and reorientation. In Cummings L. and Staw B. (eds.) Research in organization behavior, 7: 171-222. JAI Press.

Villani M., Bonacini S., Ferrari D., Serra R. and Lane D. (2007) An agent-based model of exaptive processes. European Management Review, 4: 141-151.

Wennberg, K. and Lindqvist, G. (2008) How do Entrepreneurs in Clusters Contribute to Economic Growth? Stockholm School of Economics, SSE/EFI Working Paper Series in Business Administration No. 2008-3.

White, H. (1981). Where do markets come from? American Journal of Sociology, 87: 517547.

White, H. and Eccles, R. (1987). Producers' markets. In J. Estwell and N. Milgrom (eds.), The new Pargrave dictionary of economics: (pp. 984-986). London, MacMillan.

Yu, T., Cannella, A. (2007) Rivalry Between Multinational Enterprises: An Event History Approach. Academy of Management Journal, 50: 665-686. 